\title{
Uma Antropologia Engajada: entrevista com Terence Turner
}

Edilene Coffaci de Lima

Maria Inês Smiljanic Ricardo Cid Fernandes

$U F P R$
No começo dos anos 1960, Terence Turner chegava ao Brasil e começava sua carreira como antropólogo. À procura de inteirar-se da antropologia local e em busca do domínio da língua portuguesa, freqüentou o Curso de Especialização em Antropologia Social, organizado por Roberto Cardoso de Oliveira, então oferecido no Museu Nacional/UFRJ. De lá foi aos Kayapó, para onde, de tempos em tempos, sempre volta.

A entrevista aconteceu em Curitiba, em 18 de outubro de 2007, após a apresentação da palestra intitulada "Humanidade, forma e objetivação na consciência social Kayapó", no PPGAS/UFPR, e foi concedida em português. Na primeira metade de 2009, a partir de uma intensa correspondência eletrônica, a entrevista foi editada e preparada para publicação com sua participação direta. Nela Terence Turner se declara um "privilegiado" por ter testemunhado e documentado a ascensão política dos Kayapó, que resultou na demarcação de suas terras. Também reconstrói parte de sua trajetória acadêmica e, principalmente, concentra-se nas bases conceituais que motivam seu exercício intelectual. Aposentado como professor pela Universidade de Chicago, hoje Terence Turner ensina e pesquisa na Universidade de Cornell.

Campos: Como o senhor ingressou na Antropologia?

Terence Turner: Foi um processo de eliminação. Eu saí do exército procurando algo que valesse a pena fazer na vida. Eu tinha feito, na graduação, História Moderna Européia. Então pensei que uma carreira acadêmica, como professor de uma faculdade, talvez fosse uma boa escolha. Fiz o pedido de ingresso na Universidade da Califórnia (Berkeley) em História Moderna Européia, e fiz uma especialidade em História da França da Terceira República, as políticas sócio-econômicas etc. Passei um ano em Berkeley estudando história. Isso foi em 1958-59. Naquela época, nos Estados Unidos, a abordagem da história era muito positivista, muito concentrada em estudos quantitativos, não tratava muito da dimensão cultural. Eu fiquei meio insatisfeito com as limitações metodológicas e teóricas da história. Mas, dentro das ciências sociais, a sociologia era ainda mais quantitativa e positivista, e desligada de questões de interpretação cultural. Toda a perspectiva marxista foi excluída naquela 
época. Então, as alternativas não eram muito atraentes. Por um processo de eliminação acabei na antropologia. Eu nunca havia feito antropologia em cursos; tinha lido um pouco, mas não sistematicamente.

Decidi me transferir de volta para minha universidade de graduação, que era Harvard (em Cambridge, Massachusetts), e entrar no programa de antropologia - que na época fazia parte do departamento de "Relações Sociais", que combinava sociologia (Talcott Parsons foi o grande sociólogo de Harvard na época), psicologia social e individual, e antropologia. Inicialmente pensava em fazer um trabalho de campo na França, trabalhando com comunidades de trabalhadores nos banlieus de Paris. Nos arrabaldes de Paris há comunidades de trabalhadores da mesma empresa, que vêm principalmente das mesmas comunidades rurais de várias partes da França. Eu pensei que seria interessante fazer estudos nas comunidades de origem rural e nas comunidades de trabalhadores na mesma fábrica. Não era um projeto muito interessante, mas era tudo o que conseguia imaginar. Eu também tinha feito em Berkeley, e mesmo na graduação em Harvard, estudos de história intelectual e cultural da França, e da Europa de um modo geral. Eu estudava Escola Francesa de Sociologia, Fustel de Coulanges, Durkheim, Mauss, enfim, l'Année Sociologique.

Foi quando, no segundo ano da minha pós-graduação em Harvard, chegou lá um jovem professor de Oxford, David Maybury-Lewis, que tinha trabalhado com os Xavante aqui no Brasil. Eu fiz uma espécie de tutoria, fiz seminários individuais com ele sobre o pensamento social na França, estudamos l'Année Sociologique. Quando fazia esse curso com Maybury-Lewis, ele sugeriu: "você pode ir à França quando estiver velho, com sessenta anos (isso não me parece tão velho, na minha perspectiva atual), mas enquanto jovem você deve fazer 'antropologia verdadeira' na mata amazônica, tem esse grupo jê que não foi estudado por um antropólogo bem treinado". Ele disse: "Este pode ser o foco do projeto de estudos comparativos dos grupos jê - os Jê do Norte e os Jê Central" - , porque os outros grupos tinham sido estudados até certo ponto por Nimuendajú e ele. Eu levei três segundos para dizer: "Por que não?" Nunca fui mais impulsivo em minha juventude.

Acho que foi a melhor decisão que eu jamais fiz em minha vida, realmente foi. Imaginem a sorte de ter começado o estudo dos Kayapó em 1962. Aquele ano, 1962, foi o período liminar, a beira, por assim dizer, daquela carreira de resistência da trajetória política dos Kayapó. Na época eles não tinham nenhum hectare reservado, não tinham nenhum título da terra. Cheguei ao Brasil junto com minha primeira esposa, Joan Bamberger, também antropóloga, e logo passamos a fazer parte de um grupo de alunos de um seminário em Teoria Antropológica no Museu Nacional, liderado por Roberto Cardoso de Oliveira. Nossos colegas foram Júlio Melatti, Roberto da Matta e Roque Laraia.

\section{Campos: Era o curso de especialização organizado por Roberto Cardoso de Oliveira?}

TT: Foi sim, e eu fiquei particularmente sensibilizado com a estrutura do ensino. Aprendi português (eu realmente não falava quando cheguei) e aprendi também teoria antropológica com um grupo ótimo. Foi uma experiência realmente muito estimulante. Todo mundo estava indo a campo na época para fazer estudos comparativos de fricção internética - aquela formulação de Roberto Cardoso de Oliveira sobre o contato entre grupos indígenas e as sociedades regional e nacional. Eu e a Joan fomos aos Kayapó, na aldeia de Gorotire, porque era a aldeia em que havia mais pessoas que falavam português: metade dos homens falava mais ou menos bem, e uma ou duas mulheres. Ficamos lá dez meses. Esforcei-me para aprender a falar Kayapó. Levei nove ou dez meses para chegar 
a um domínio qualificado. Depois fui para Kubenkrãkên, uma "comunidade-irmã", por assim dizer, de Gorotire, mas onde poucos falavam português. Fiz um segundo período de estudos lá, voltei aos EUA e escrevi a tese. Joan também realizou uma pesquisa antropológica para seu doutoramento em Harvard, sobre a ecologia conceitual dos Kayapó. Em 1965 voltei a campo, mas dessa vez ao Xingu, com um grupo que se chama Mentuktire - na época chamava-se Porori. Daí para frente fiquei dez anos sem voltar aos Kayapó. Até então eu tinha realizado somente análises clássicas, por assim dizer: parentesco, estrutura política, descrições dos cerimoniais coletivos, mas sem muitas análises dos mitos. Comecei a fazer uma análise dos mitos Kayapó porque eu fiquei muito insatisfeito com a abordagem lévi-straussiana dos mitos.

Em 1976 a BBC de Londres me propôs levar uma equipe de televisão para fazer uns filmes etnográficos dos Kayapó e eu aceitei. Assim, voltei a campo no momento dos primeiros movimentos kayapó de reconquista de seu território. Estava em discussão a BR-080, aquela estrada que o governo brasileiro tinha secretamente construído e desviado do curso, avançando ao norte do Parque do Xingu. O Ministro do Interior, acho que se chamava Cavalcanti ${ }^{1}$, tinha conspirado com empresas de grileiros, imobiliárias e fazendas para cortar toda essa seção do Parque e vendê-la para particulares. Os Kayapó tinham mudado comunidades inteiras para lá porque os diretores do Parque, os irmãos Villas-Boas, tinham insistido para que voltassem para sua antiga área, que ficou dentro dos limites do Parque, para ficarem mais seguros. Eles estavam lá e, de repente, deram-se conta de que foram traídos pelo governo.

Começou um movimento de resistência que foi uma semente, foi o ponto embrionário do desenvolvimento dessa campanha brilhante que se desenrolou nos anos seguintes. Houve luta armada e por volta de cinquenta invasores e grileiros brasileiros foram mortos em assaltos que os Kayapó fizeram contra os posseiros, caçadores de peles, pescadores e fazendeiros. Também capturaram os garimpos que tinham sido abertos a leste. Levou quase vinte anos, mas finalmente o governo recuou e concedeu todo o território que ele tinha tentado cortar e declarou esse território como reserva kayapó. A partir de então, uma série de outras demarcações deixou os Kayapó com mais ou menos 150 mil quilômetros quadrados. É bastante mais que a área da República Tcheca, para uma população de mais ou menos sete mil pessoas atualmente. Foi uma combinação de luta armada, diplomacia muito inteligente, manipulação de imagem e utilização de meios de comunicação contemporâneos, como televisão, rádio e mídia impressa. Em consequência, acho que os Kayapó se tornaram o grupo indígena talvez mais imponente e bem conhecido popularmente em todo o país. Eu me sinto muito privilegiado de ter sido capaz de acompanhar essa carreira do início até o presente.

Campos: O senhor acompanhou essa carreira do início até o presente, como acabou de falar. Pelo menos dois Terry Turner estiveram presentes: um intelectual, pensador, etnógrafo, e outro militante, parceiro ou colaborador. Como o senhor vê essas duas faces do trabalho antropológico?

TT: Bem, vou ensaiar duas respostas, apropriadas aos dois Terry Turner. Primeiro, eu sempre estive alinhado com uma política de esquerda, eu sempre estive convencido de que a teoria social deve informar uma política ativista. Se a antropologia tinha algo a dizer à sociedade em geral, deveriam ser coisas que ajudassem a formular uma política de melhoramento da sociedade, inclusive de minorias como as sociedades indígenas, em todos os países, e não somente no Brasil. Essa não é uma idéia original, mas esses grupos marginais são, por assim dizer, espelhos 
que mostram assuntos fundamentais, problemas fundamentais da própria cultura, da política, da organização social da sociedade hegemônica, envolvente. Eu sempre achei fundamentalmente errônea a divisão que se estabeleceu na antropologia norte-americana entre a chamada applied anthropology, de um lado, e a antropologia acadêmica, do outro lado. Na América Latina, inclusive no Brasil, essa é a divisão que se dá entre a antropologia teórica e o indigenismo. Ao longo da minha carreira eu escrevi algumas vezes sobre esse assunto. Acho que meu primeiro artigo em português foi aquele que eu escrevi para o encontro de antropólogos patrocinado pela ABA e pela ANPOCS em Belém, em 1987, chamado “De Cosmologia a História"² (tradução em inglês: "From cosmology to ideology"), que tomou como tema a relação entre a teoria antropológica e o ativismo, clamando por uma abordagem sintética entre a compreensão e os esforços ativistas no apoio à luta pelos direitos indígenas - direitos territoriais, direitos humanos e independência relativa social e cultural.

Segunda resposta (do segundo T. Turner): eu acho que nas tradições intelectuais antropológicas principais que nós temos no Ocidente (a tradição francesa, a tradição alemã, a tradição inglesa e a dos EUA) sempre houve um engajamento no sentido de formular programas de ação, de melhorar a sociedade, de dar à cultura formas mais capazes de promover o desenvolvimento de capacidades humanas. É verdade que uma vez convertidas em especialidades acadêmicas, muitas dessas teorias se tornam abstratas, ou abstraídas do contexto da luta social, cultural e ideológica no qual se originaram. Mas eu acho fundamental não esquecer como essas teorias se originaram, elas ainda têm sentido como tentativas de orientar a luta contra a injustiça, em direção a formas mais justas e humanas de sociedade e cultura. Isto é verdadeiro sobretudo em relação aos trabalhos com grupos de culturas diferentes, como os grupos indígenas.

Vistas na perspectiva antropológica, a gente percebe rapidamente que essas nossas finalidades, como "justiça" e "realização de valores culturais", são muito diferentes do que esses termos significam para as minorias indígenas. Nossas especialidades, na frase de Marx, "só têm um lado, não têm todos os lados" - são one sided, not all-sided. Essa frase é hegeliana originalmente. Indigenismo (no Brasil) e applied anthropology (nos EUA) são geralmente formulações one sided que consideram absurdas as nuanças de diferença cultural, os propósitos, os valores significativos da luta social e da política de grupos indígenas que eles estavam tentando ajudar: "ajudar" sem sensibilidade cultural, tipicamente para transformá-los em gente como nós. Mas não é possível ficar numa aldeia kayapó muitos dias sem perceber que eles não têm o menor interesse em se transformar em gente como nós. Eles têm suas próprias pistas de desenvolvimento, eles sabem o que querem fazer, eles querem transformar sua situação em vários aspectos, mas não para se transformarem em brasileiros, americanos ou em homens do Ocidente, de jeito nenhum. Então acho que um domínio etnográfico, uma verdadeira compreensão (compreensão talvez seja forte demais) ou familiaridade etnográfica, honesta e aberta, conduz fatalmente a perceber a natureza dos goals (objetivos), da luta, dos esforços e aspirações do povo com o qual a gente está morando e interagindo. Assim, eu não compreendo como os etnólogos, os antropólogos, nessas situações, podem ficar fora do engajamento. Nessas lutas acontece uma espécie de osmose entre etnografia, compreensão teórica e apoio aos seus esforços. É engajamento e ativismo. Acho realmente a tentativa de dividir esses dois aspectos artificial e insustentável. 
Campos: Quando o senhor veio ao Brasil para fazer trabalho de campo pela primeira vez já tinha essa compreensão ou esse foi um processo mais longo?

TT: Não, no início eu não sabia o que estava fazendo, sinceramente. Se isso que eu disse parece uma posição sistemática, não era essa a situação do meu pensamento quando cheguei aqui. Eu tinha minha política, era destemidamente esquerdista, mas era completamente formulada em termos da política das sociedades industrializadas do primeiro mundo, eu era um social-democrata de esquerda. Era uma posição confortável para um jovem universitário. Mas essa política não se estendeu para a atividade etnográfica, antropológica. Essa compreensão de que falo agora foi um trabalho de muitos anos.

Campos: Gostaríamos que o senhor falasse um pouco também sobre a sua inserção no Projeto Harvard-Brasil Central e sobre a relevância desse projeto na sua carreira.

TT: Bem, houve também pontos de divergência. Primeiro, a orientação do projeto de Harvard foi o neodurkheimianismo de [Rodney] Needham, tal como formulado em Oxford, e tomado mais ou menos palavra por palavra por David Maybury-Lewis. Essa foi uma abordagem, a meu ver, essencialmente idealista. Tratava-se de uma análise formalista de sistemas de classificação, enfatizando a oposição dualista etc. O chamado angloestruturalismo focalizou em terceiros elementos mediadores entre categorias dualisticamente opostas, como em alguns trabalhos de Mary Douglas e de Edmund Leach, nos quais aparecem elementos mediadores com propriedades quase mágicas ou místicas.

Apareceu também a mesma tendência nos estudos de estruturas rituais, como aparece mais fundamentalmente na obra de Van Gennep. Uma coisa que faltou nesses trabalhos todos, em toda essa teoria, foi uma capacidade de integrar a estrutura simbólica com a práxis social, não somente no sentido de reflexo da organização normativa social, mas como esquemas de atividades que produzem relações e pessoas sociais. Em poucas palavras, faltou a possibilidade de analisar processos mais ativos de transformação como totalidades ao mesmo tempo materiais, sociais e conceituais.

Na formação de meus colegas do projeto Harvard-Museu Nacional, que posso chamar de ortodoxos nesse contexto, essa tendência apareceu como uma espécie de dança das categorias. Vida social não é isso, o problema sempre me pareceu compreender como alguns processos de ação social - os conflitos sociais - se relacionam à consciência social. E sempre me pareceu que antropologia era isso: uma tentativa de chegar a uma compreensão sintética entre ação social (quer dizer, ação política, econômica, histórica) e formulações e transformações de consciência social, de cultura. Cultura, nessa imaginação neo-durkheimiana, era composta essencialmente de classificações. Era um modelo profundamente estático, que conservava a forma do positivismo durkheimiano no plano idealista.

Esse fascínio com elementos mediadores, como aparece em alguns trabalhos de Mary Douglas e de Edmund Leach, conseguiu seu destaque, seu sucesso. Os elementos mediadores pareciam oferecer uma saída dessa análise estática da classificação em direção a um processo mais dinâmico. Mas isso ainda aconteceu no chão de baile, quer dizer, da dança das categorias. Mesmo que essa análise fosse uma espécie de representação dos processos sociais, com passagens de estados, como acontece nos ritos de passagem, dentro dessa tradição 
ninguém jamais abordou qual era a natureza do vínculo entre essas passagens sociais e as representações (os mitos, por exemplo) dessas passagens. Alguns dos meus primeiros artigos foram reestudos sobre ritos de passagem da obra de Van Gennep e de Victor Turner, que até certo ponto tomou Van Gennep como modelo; e também de mitologia, um problema paralelo na análise estruturalista de mitos de Lévi-Strauss. Havia pontos cegos na negação da dimensão narrativa das narrativas mitológicas. Eu fiquei convencido de que o essencial era formular modelos de estrutura que fossem, ao mesmo tempo, modelos de processos de mudança dentro das histórias mitológicas. Isto porque os mitos são narrativas de transformação, coisas acontecem; mas no estruturalismo nada acontece.

Então me pareceu óbvio que esse era um ponto cego que eles compartilharam com as formulações durkheiminianas, e que Lévi-Strauss compartilhou, em todo caso, por exemplo na reanálise do mito de Édipo.

Eu achei essencial fazer a mesma coisa no campo de estudos das sociedades jê amazônicas. Era preciso investigar como essas estruturas tão aparentemente cristalinas (com metades, classes de idade, formas circulares e geométricas de aldeias) se relacionavam aos processos de desenvolvimento social, das propriedades estruturais desses grupos. Nenhum trabalho do projeto de Harvard, de Maybury-Lewis, abrangia essa problemática. Eram todos estudos categoriais, de classificação, da estrutura da aldeia, da relação classificatória com o outro mundo. Eu achei que uma contribuição fundamental era mostrar que essas formas aparentemente cristalinas eram, na realidade, formulações dos pontos-chave de transformação nos processos de reproduzir os elementos fundamentais da estrutura. Em poucas palavras, essas estruturas eram sistemas hierárquicos (no sentido formal) onde unidades estruturais eram reproduzidas em outro nível, num nível mais alto, por assim dizer, que compartilhava os pontos essenciais do processo de reproduzir as unidades do primeiro nível. Um sistema de feedback, que se retroalimenta.

Havia outra diferença fundamental, outro elemento que faltou nos estudos do projeto de Harvard: observar que esses sistemas são sociedades humanas, não são máquinas ou computadores, acumuladores de informação, onde o feedback responde a cognatos inseridos por seres humanos localizados fora do sistema. Quer dizer, esses sistemas são impulsionados pelos esforços de seus membros, de indivíduos humanos, e adquiriram valores que eles acharam que valiam a pena para reproduzir esse sistema. A gente tinha que compreender como esses valores foram produzidos pelo mesmo processo que produziu as relações na estrutura. Isso remeteu à necessidade de uma teoria de valor que pudesse estar ligada a uma teoria de estrutura, o que, por sua vez, remeteu a Marx. Somente Marx ofereceu uma abordagem de valor gerado pela organização do próprio processo de produção, ou assim a questão me pareceu. Então desenvolvi uma versão bastante preliminar, um modelo comparativo das sociedades brasileiras de língua jê e bororo formulado segundo essas linhas. Esse modelo foi caracterizado pejorativamente por Maybury-Lewis na introdução do livro produzido pelo grupo, Dialectical Societies, como "marxista", que não era para ele uma palavra positiva, porém estava bem para mim. $\mathrm{O}$ "marxista" indicava para ele um tipo de rebelde, alguém que se desviou do grupo.

Esta é a breve história do desenvolvimento da abordagem da sociedade jê que eu fiz. Quero mencionar que o único membro daquele grupo de Harvard que chegou a concordar comigo a esse respeito foi Jean Lave, que escreveu uma reanálise brilhante do sistema social dos Ramkokramekrã-Canela a partir do modelo que eu tinha sugerido. O David Maybury-Lewis se recusou a incluir o artigo dela no livro Dialectical Societies e então Jean Lave o publicou nos Actes de la Société Internacional des Américanistes de 1976². Depois ela saiu da antropologia, 
foi estudar educação. Com a única exceção dela, este modelo não foi seguido nem por Maybury-Lewis, que sempre se declarou incapaz de entender o que eu estava querendo dizer, nem por outros membros do projeto de Harvard, nem por algum outro antropólogo francês ou inglês trabalhando com sociedades amazônicas. Outros amazonistas estadunidenses, com raras exceções, ficaram completamente indiferentes a esse tipo de esforço.

De minha parte, tenho tentado desenvolver o modelo em vários sentidos. Fiquei convencido de que eu realmente tinha que fazer um esforço gigantesco para compreender Marx, para merecer verdadeiramente o epíteto de Maybury-Lewis. Eu nunca tinha estudado Marx - nem na graduação, nem na pós-graduação. Naquela altura, em 1964-67, os movimentos contra a guerra do Vietnã e em defesa dos direitos civis foram encaminhados. Nesses movimentos havia muitos grupos de leitura, tinha gente lendo todas as coisas: teoria social, Marx e outros que eram relevantes para a compreensão da luta, da mudança social, dos processos sociais. Eu participei de alguns destes grupos e foi neles que ganhei meu primeiro conhecimento sério de Marx. Ao mesmo tempo eu tinha conseguido um emprego, primeiro na Universidade de Cornell. Dois anos depois mudei para a Universidade de Chicago. Como professor eu tinha o direito de ensinar coisas de teoria social, inclusive Marx. Então incorporei Marx em um dos grupos de leitura, como seminário oficial da universidade. Fiquei ensinando, mas também lendo, aprendendo e falando. Esse foi o primeiro passo do desenvolvimento de uma série de cursos baseados nas obras do próprio Marx, e não nos seus comentadores. Eu sempre fiquei fortemente alienado em relação aos antropólogos marxistas franceses, por exemplo, da tradição althusseriana. Althusser, Foucault, todos os franceses estruturalistas e pós-estruturalistas, realmente eu não ligo. Não considero Althusser um marxista, parece-me um filósofo funcionalista. Concordo com quase cada palavra de Edward Thompson sobre Althusser no seu livro $A$ Miséria da Teoria (The Poverty of Theory). Nesse livro, numa crítica devastadora da abordagem althusseriana, ele disse: "Se Althusser é marxista, eu jamais poderia ser marxista".

Campos: O senhor destacou o percurso que fez até chegar à compreensão do dualismo como uma teoria social. Continuando no mesmo tema: como resumiria as possibilidades de diálogo - mesmo que crítico - com o angloestruturalismo e o estruturalismo francês?

TT: Tocamos em alguns pontos sobre este assunto. Cabe acrescentar que a formulação neo-durkheimiana de Needham e outros, de oposição dual, não era a formulação propriamente estruturalista de oposição binária proporcionada, por exemplo, por [Roman] Jakobson e pela Escola de Praga. Para eles a oposição entre dois pontos, para ser verdadeiramente estrutural, deveria ter um outro ponto que partilhasse uma relação idêntica entre os dois pontos da oposição. Oposição binária é realmente uma coisa complexa, uma superposição de oposição e identidade. A obra de Needham nunca identificou um fundo de identidade entre os dois opostos. O chamado anglo-estruturalismo, assim, não era mesmo uma formulação estruturalista, era um neo-durkheimianismo. Eu fiquei pensando que ninguém tinha compreendido a natureza de metades como organizações estruturais neste sentido: apenas Lévi-Strauss, que tinha tido uma concepção fundamentalmente estruturalista de metades. Estou me referindo aqui ao seu artigo "Les Organisations Dualistes Existent-Elles?" - não a seu tratamento de metades exogâmicas em Les Structures Elementaires de la Parenté -, pois ele remete a uma combinação de hierarquia com simetria, de igualdade e desigualdade ou, em outras palavras, a uma justaposição complexa de duas dimensões, uma de oposição, outra de relativa identidade. Sua formulação neste artigo era mais próxima de Jakobson e da 
Escola de Praga, mas essa formulação tinha de ser posta em uma moldura analítica socialmente baseada.

A conclusão à qual eu cheguei é muito simples: essas metades, com as suas semelhanças, comportam uma dimensão de oposição e desigualdade que é, no fundo, de caráter social e político, em vez de puramente simbólico ou ideológico. Nesta ótica, sistemas de metades aparecem como mecanismos pela neutralização de tensões provenientes de desigualdades sociais. Por exemplo, pode-se pensar numa hierarquia de classes de idade: o sistema fica instável porque os jovens, embaixo, estão sempre pressionando contra a hegemonia dos anciãos (seniores). No caso dos Kayapó, esse sistema se tornou ainda mais instável quando eles estavam fazendo a resistência militar em defesa do território: o que exagerou a tensão hierárquica foi o papel aumentado dos líderes de grupos de guerreiros. O próprio sistema, a estrutura da sociedade de metades rachou. Por que? Porque o aspecto do sistema que tende a neutralizar desigualdades interferiu demais com a tendência oposta de destacar a dominância da liderança dos guerreiros. Para compreender isso podemos fazer um exercício de pensamento. Se há um eixo de desigualdade - pense este eixo como vertical - e esse eixo se replica horizontalmente com estrutura idêntica, igualmente instável, tal como as pressões verticalmente direcionadas, e se esses eixos se viram um contra o outro, isto faz com que essas pressões de aniquilem. Um eixo neutraliza o outro, porque as pressões de um estão dirigidas contra as pressões correspondentes do outro eixo.

Esta é uma maneira muito simples de converter um sistema de desigualdade assimétrico em um sistema simétrico de neutralização de pressões instáveis, um sistema horizontalmente estável. É uma teoria de dualismo que liga a forma categórica à forma de conflito político para explicar a instabilidade histórica, que remetia aos processos de produção do sistema social e também aos valores do sistema no sentido que eu vinha falando antes.

Eu tenho publicado várias críticas neste sentido tanto ao anglo-estruturalismo como ao estruturalismo. Não sei se elas tiveram muito efeito. Ao mesmo tempo tentei desenvolver uma armação teórica mais adequada, num sentido positivo e construtivo, dessas formulações anglo-estruturalistas e lévi-straussianas. Eu sinto que essas críticas, essas formulações construtivas, chegam a ser os pensamentos mais sérios da carreira que eu tentei percorrer. Tentei explicá-los num artigo sobre as estruturas e formas de ritual em um texto recente, que acaba de ser publicado em um livro alemão, mas com título e artigos em inglês, que se chama Theorizing Ritual. Os organizadores me convidaram a escrever o capítulo "Structure, Process, Form". Muitas das críticas ao estruturalismo e ao anglo-estruturalismo que eu resumi agora estão mais claramente articuladas neste artigo ${ }^{4}$.

Campos: O senhor ainda se considera um antropólogo marxista? Em que consiste ser um antropólogo marxista hoje nos EUA?

TT: Eu me considero um antropólogo marxiano. Quem segue Durkheim não se chama durkheimista, e sim durkheimiano. Marxista tem que ser alguém que adere à Terceira Internacional, alinhando-se assim com os marxistas-leninistas: eu nunca fui leninista. Também não tenho muito a ver com o marxismo da Escola de Frankfurt. Todas essas posições vêm junto com o adjetivo marxista. Então eu me chamo marxiano para enfatizar que para mim o trabalho de Marx é fundamental e contém muitos elementos que faltam em posições marxistas posteriores. Por exemplo, para nós a teoria de valor é uma teoria de como valor comporta um papel crucial pela mediação semiótica, isto é, pelo dinheiro, e por todas as formas de dinheiro, como o crédito, sem o qual o valor não pode existir. 
Todo essa parte do pensamento de Marx foi deixada de lado, foi ignorada ou descartada por marxistas ortodoxos do tipo Terceira Internacional como um elemento idealista, e assim retrógrado, no pensamento de Marx, e por pensadores marxianos que seguiram Marx. Uma tarefa fundamental da teoria antropológica, e não somente da teoria marxiana, a meu ver, é reformular o lado essencial das idéias de Marx sobre o valor, inclusive da mediação (media) semiótica de valor. Um exemplo é o dinheiro, mas há outros. Se pudermos chegar a uma formulação mais geral dessas ideias, poderemos aplicá-lo a sistemas de produção social que não estão baseados na produção, circulação e intercâmbio de mercadorias: como os Kayapó, por exemplo, ou todas as sociedades amazônicas, que não têm sistemas de produção baseados sistematicamente na produção de mercadorias - em outras palavras, não têm economias no sentido exato, não têm mercados. Têm trocas simbólicas? Sim, mas de coisas especializadas que não representam produção social como totalidade, um critério essencial de valor no sentido econômico. Por exemplo, produzem enfeites que têm um significado todo especial, que são importantes, mas que não são mercadorias no sentido econômico.

Esses são sistemas de produção não-econômicos, no sentido específico de não serem baseados em mercadorias: existem para reproduzir pessoas sociais e sistemas sociais, instituições comunitárias, todo esse tipo de coisa. Esses sistemas podem ser considerados como sistemas que produzem valor, e até talvez algo análogo à mais-valia, uma vez que uma parte desse valor é distribuída desigualmente, de tal maneira que um grupo dominante que controla o processo de produção ganha uma parte desproporcional. É o caso dos sogros dominando os genros e ao mesmo tempo ganhando mais valor social ligado ao seu status, de modo que, quanto mais velho, mais bonito, mais livre e mais dominante. Elaborei este argumento pela primeira vez no artigo que escrevi no livro de Maybury-Lewis, Dialectical Societies. Lá eu falei em “hierarquia rotativa” ${ }^{\text {, }}$ porque os dominantes de hoje sempre estão em vias de desaparecer, enquanto os dominados vão envelhecendo e assim se tomando os novos dominantes. Por esta expressão quis assinalar que entre os Kayapó essa hierarquia de grupos de idade está continuamente em movimento, e isso é diferente de um sistema de classes fixas. Essas ideias aparecem também num outro artigo publicado no número atual da revista Anthropological Theory, uma revista da Suécia. É uma edição dedicada à análise das teorias de valor na antropologia, chama-se Values of Value. ${ }^{6}$ Meu artigo se chama "Marxian value theory: an anthropological perspective" e é minha reformulação mais recente sobre a aplicação da teoria de valor marxiana às sociedades não-econômicas como as da Amazônia indígena.

Modifiquei uma ideia sobre valores Kayapó depois daquele artigo no Dialectical Societies, no qual eu disse que havia realmente duas categorias de valor entre os Kayapó: uma, que chamei de beleza, das coisas bonitas, belas, num sentido muito geral, como um princípio estético; mas também haveria uma outra categoria que chamei de dominância, pois eles também valorizam o poder, a influência de lideranças que podem preservar a paz social e garantir a própria produção de beleza. Haveria então uma relação complementar entre esses dois valores. Hoje acho que foi um erro meu qualificar dominância como valor, no mesmo sentido de beleza. Pois talvez realmente eles definam beleza como acumulação, como o aperfeiçoamento de todas as partes de uma totalidade. Dominância, poder, é a capacidade de efetuar o processo de produção de beleza. Em nossas sociedades, a capacidade do Estado de garantir o mercado e a circulação de mercadorias é fundamental para garantir o sistema de produção de valor. Mas isso não quer dizer que o Estado, o poder político, em si mesmo, é uma forma de valor. Eu acho que, analiticamente, eu falhei ao fazer esse tipo de distinção. É necessário uma teoria de poder, especialmente agora que temos 34 anos $^{7}$ com essa besteira foucaultiana de falar de poder sem ter alguma teoria de poder. 
Campos: No artigo "De Cosmologia a História"8 o senhor afirma que houve, desde aproximadamente a década de 1980, uma transformação da consciência social dos Kayapó, que teriam passado a se conceber como agentes de sua própria história. Na leitura de seu trabalho se tem a impressão de que essa transformação da consciência social kayapó implicou certo rompimento com a consciência mítica, que teria prevalecido no período anterior. Teria mesmo havido uma ruptura entre essas duas formas de apreensão da realidade pelos Kayapó? Quais são suas reflexões sobre esse assunto hoje?

TT: Em primeiro lugar, essa formulação é da metade de 1980, mas, seja em qual ano for, foi uma formulação obviamente tosca e crua. A sociedade kayapó em vários aspectos continua a ser baseada em uma consciência mítica. Antes de 1980 eles já eram conscientes de vários aspectos de sua agência com atores externos, mas não eram assim tão conscientes da natureza da sociedade envolvente e da sua capacidade de enfrentá-la frontalmente. Antes a relação deles com a sociedade brasileira era essencialmente sua relação com a sociedade regional, representada principalmente por caçadores e seringueiros - não havia madeireiros ou garimpeiros ainda por lá e também pelas frentes pastoris de Pau d'Arco, na região do Araguaia. Essas eram formas bastante vulneráveis da sociedade envolvente. As relações com os Kayapó eram mais ou menos iguais ou até desiguais em favor dos Kayapó, visto que estes formavam grupos grandes, podiam mobilizar grupos de homens armados, ao passo que esses representantes da sociedade regional eram fazendeiros isolados, grupos pequenos de caçadores e de seringueiros e podiam ser, mais ou menos facilmente, vencidos em conversas. Disseram-me que quando os grupos kayapós do Sul do território atual, os Gorotire e os outros grupos que compõem o atual Território Indígena Kayapó foram contatados - alguns entre 1938-40, outros só nos anos 50 - , todos os homens de idade militar nas aldeias estavam com armas de fogo. Os caçadores e seringueiros pouco resistiram. Então, os Gorotire percebiam sua agência frente a uma parte da sociedade nacional, mas a pacificação foi para eles, mais ou menos rapidamente, uma experiência de desmoralização. Eles ficaram rapidamente dependentes, como mendigos, como se tivessem perdido a agência por isso.

Paulatinamente eles chegaram a uma compreensão mais ampla da natureza da sociedade brasileira como totalidade. A existência de postos do SPI e depois da FUNAl, essa era a dependência que eles tinham. Nos primeiros anos do contato a consciência mitológica da natureza da sua sociedade explicou todas as formas tradicionais de sociedade. No início, eles não tinham qualquer ideia sobre como reverter os termos desiguais das relações com a sociedade nacional, especialmente no contexto dessa dependência. A possibilidade de reversão começou somente nos anos 1970, quando os Kayapó passaram a ter uma visão de resistência nas várias situações, e também começaram a fazer manifestações em Brasília, nos últimos anos da ditadura, quando o presidente era o [João Baptista] Figueiredo. Durante a ditadura houve uma manifestação no Palácio do Planalto à qual os Kayapó foram armados, pintados, cantando em voz alta, chamando uma cobertura midiática sensacionalista. Isso causou uma sensação em nível nacional. Assim também se revelou um arranjo secreto com a Argentina para fazer na Serra do Cachimbo um depósito de lixo radioativo. Os Kayapó atingiram o alvo de suas manifestações e nenhum deles foi preso - e essa foi a primeira de uma série de manifestações. Mais ainda, conseguiram ganhar muitos aliados: organizações não-governamentais, antropólogos, eles tinham a capacidade de organizar e mobilizar apoios. Tudo isso entrou numa atitude que chamei mais propriamente de histórica. Não se trata mais de conversar com fazendeiros para fazer suas redes, era todo um outro nível de compreensão, era isso que eu 
tinha em mente naquele ensaio. Acho que eu realmente não exprimi bem essas idéias, era uma formulação muito tosca. De todo modo, ainda acho essencialmente correto afirmar que o sucesso dos Kayapó em recuperar todo o território perdido, ou quase todo, é o sucesso, acima de tudo, da sua própria revolução de consciência. Não foram simplesmente manifestações espontâneas, não há nada de espontâneo.

Campos: Em alguns de seus estudos o senhor dialoga com a antropologia brasileira e se serve do conceito de fricção inter-étnica. Qual o diálogo que o senhor mantém com os antropólogos brasileiros e com a antropologia produzida no Brasil?

TT: Eu tenho diálogos diferentes, com antropólogos diferentes. Por exemplo, com Eduardo Viveiros de Castro, que fez uma visita ao Departamento de Antropologia da Universidade de Chicago quando eu era professor lá, e com quem depois eu fiz parte de um seminário em Paris, na EHESS (École des Hautes Études en Sciences Sociales). Fizemos parte do seminário de Philippe Descola, que proporcionou oportunidades de diálogo entre nós muito estimulantes. Outro tipo de diálogo tenho tido com o pessoal do Núcleo de História Indígena da Universidade de São Paulo, especialmente com Dominique Gallois, que há anos lida com projetos que a mim parecem exemplos de trabalhos bem pensados e, ao mesmo tempo, eficazes, como ativismo. Em acréscimo, ela também trabalha com vídeo, com o qual eu estive lidando com os Kayapó - este também foi mais um ponto comum. Assim, nós temos tido sempre um diálogo intenso. Com a parceria de Vincent Carelli, do projeto Vídeo nas Aldeias, eu tenho trabalhado todo o meu projeto de vídeo dos Kayapó e a formação do arquivo de vídeo kayapó. Foi com o apoio dele, na ilha de edição do Centro de Trabalho Indigenista, quando estava ainda em São Paulo, que eu aprendi como trabalhar o vídeo e as suas possibilidades, aprendi a explorar antropologicamente essas possibilidades. Aprendi algumas coisas para repassar aos Kayapó, para eles próprios fazerem seus vídeos. Haveria outros nomes a mencionar: Alcida Ramos, meus velhos colegas da PPGAS do Museu Nacional, Roberto da Matta, Roque Laraia e Julio Melatti. Eu acho que a antropologia brasileira é um cenário muito variado e muito rico. Há muitos anos eu tenho sido continuamente desafiado, estimulado e enriquecido por esses bons contatos.

Campos: O senhor destacou as convergências, mas em sua resposta podemos entender que há também alguma divergência. Quais seriam, por exemplo, as divergências com o trabalho de Eduardo Viveiros de Castro e, particularmente, com o perspectivismo?

TT: Meus debates acadêmicos com Eduardo Viveiros de Castro ao longo dos anos remetem em parte a nossas orientações teóricas diferentes - no caso dele, estruturalismo, e no meu caso uma mistura de antropologia social, anglo-estruturalismo, o Année Sociologique e Marx. Em parte também as nossas diferenças remetem, sem dúvida, a nossas experiências etnográficas divergentes: no caso dele com os Araweté, um pequeno grupo Tupi com estrutura social e cosmologia mais ou menos típicas das sociedades do tipo "Floresta Tropical" (aldeias relativamente pequenas e exogâmicas, com sistemas sociais relativamente simples, focalizados em relações com grupos externos); no meu caso, com os Kayapó, grupo Jê de aldeias grandes e efetivamente endogâmicas, com sistema social internamente focalizado em rituais comunais e uma hierarquia relativamente complexa de grupos coletivos. Estas diferenças sociais, pois, podem resultar em diferenças ideológicas que podem afetar 
perspectivas cognitivas tanto dos dois tipos de sociedades, como dos seus antropólogos. Assim, não posso excluir a possibilidade de que tais divergências possam ter entrado nas minhas ressalvas a algumas das generalizações de Eduardo Viveiros de Castro sobre as ideias supostamente comuns de sociedades amazônicas, ou mesmo "ameríndias". Seja como for, tenho uma série de críticas etnográficas, teóricas, metodológicas e até lógicas ao edifício teórico erigido por Eduardo Viveiros de Castro e alguns dos seus alunos e colaboradores, que em seu conjunto vem sendo conhecido como "perspectivismo".

O perspectivismo, enquanto perspectiva teórica, é essencialmente uma forma revisionista de estruturalismo lévi-straussiano, que pretende reter os traços essenciais do esboço teórico estruturalista e ao mesmo tempo inverter seu cerne conceptual: a noção da oposição de natureza e cultura como o princípio axiomático das cosmologias dos grupos indígenas das Américas. O projeto analítico do estruturalismo ortodoxo, porém, é demonstrar que esta oposição - e a fortiori todo o edifício de cultura baseado nela - é, em si mesma, um produto do agenciamento do processo psicológico (e, por isso, natural) de percepção, e a construção, através de associações psicológicas, de representações conceptuais das formas naturais do mundo transmitido pela percepção, assim terminando na redução da cultura a uma emanação de natureza. O perspectivismo pretende preservar a forma reducionista do projeto estruturalista mas de forma inversa, visando a redução da natureza à cultura. Isto me aparece uma forma teórica de saltar da frigideira para o fogo. Em ambos os casos, acaba-se longe da perspectiva cultural dos povos indígenas, ao menos como eu a comprendo, que se assemelha mais a uma mediação das duas extremidades da oposição, em vez de uma opção por uma e exclusão da outra.

Estas ressalvas conceituais se baseiam em desacordos sobre a interpretação de dados etnográficos, por exemplo o mito (ou melhor, o conjunto de mitos) citado por Eduardo Viveiros de Castro como a base de sua afirmação de que os índios da Amazônia acreditam que os animais se identificam com a gente, isto é, veem a si mesmos como seres humanos e, portanto, possuidores de cultura humana. Esta é sem dúvida a tese do perspectivismo mais bem conhecida: os animais, tomados pelo pensamento ocidental (inclusive pelo próprio estruturalismo) como os representantes prototípicos de "natureza" no sentido oposto a "cultura" humana, segundo o pensamento indígena não se concebem, eles mesmos, como entidades naturais: a própria natureza, pois, segundo a concepção dos índios, rechaça subjetivamente o caráter de natureza e adota a perspectiva cultural de humanidade. Os mitos que o Eduardo Viveiros de Castro cita como evidência para esta afirmação surpreendente recontam que, era uma vez, seres humanos e animais coexistiam numa base de quase-identidade, compartilhando linguagem e até, em alguns casos, se casando. Este momento idílico descrito pelos mitos é o que Eduardo Viveiros de Castro aproveita como o ponto de partida da perspectiva teórica do perspectivismo.

Olhando mais de perto, porém, dá para ver que os mitos deste conjunto não apóiam a interpretação de Eduardo Viveiros de Castro, por várias razões. Logicamente, começaremos por reconhecer que o convívio entre seres humanos e animais que os mitos descrevem como o ponto de partida dos seus enredos é uma situação simétrica de não-diferenciação, que implicava tanto o compartilhamento da natureza dos animais pelos homens como a participação dos animais nas capacidades dos homens. Os homens ao início da história não eram ainda completamente humanos, ainda não tinham cultura no sentido pleno da cultura atual, enquanto os animais não eram também completamente animais, como o são os animais contemporâneos. Esta condição de relativa não-diferenciação e de indefinição em ambos os lados era a precondição da interação e da participação mútua dos antepassados míticos dos bichos e dos seres humanos nas vidas uns dos outros. Interpretar esta 
situação de convívio como evidência de uma relação de identificação assimétrica e não recíproca de animais com gente, em sua forma plenamente diferenciada e culturada é, portanto, duplamente errado, porque ignora a participação recíproca dos antepassados humanos na condição dos animais e falha em reconhecer que os seres humanos ancestrais não eram como os humanos de hoje, com cultura plenamente desenvolvida. Podemos notar de passagem que esta interpretação assimétrica parece surgir de uma proclividade antropocêntrica, porém prematura, uma vez que homens, no sentido próprio, ainda não existiam.

De toda maneira, tomar a situação de convívio não-diferenciado das formas ancestrais de bichos e de gente, que constitui a fase inicial dos mitos de origem da cultura, como a base de uma afirmação de que os bichos de hoje em dia continuam a se relacionar subjetivamente com os seres humanos da mesma forma que os seus antepassados é ignorar a meta destas histórias. Elas sempre contam que no fim da época mítica os animais perderam a capacidade de falar com homens e todo o resto dos traços e comportamentos culturais objetivos. Em termos gerais, pois, a meta dos mitos deste conjunto é explicar como os homens e os animais se diferenciaram definitivamente uns dos outros, os homens perdendo os seus traços de animalidade e os bichos, reciprocamente, perdendo os seus traços culturais. Em suma, é explicar como desapareceram para sempre as condições de identificação mútua dos antepassados de bichos e gente na época mítica. A causa deste salto evolucionário é sempre, implícita ou explicitamente, o desenvolvimento de cultura, no seu senso moderno, pelos seres humanos. Eduardo Viveiros de Castro desconsidera a finalidade desta diferenciação dos animais, e o papel da cultura nela, insistindo que os mitos implicam que a identificação deles com a humanidade e a cultura meramente se internalizou, e continua subjetivamente como a perspectiva espiritual dos animais. Assim, os animais contemporâneos supostamente se identificam como seres humanos e concebem suas próprias atividades animalísticas como se fossem atividades culturais (assim a onça, engolindo o sangue da sua presa, imagina que está bebericando cerveja de mandioca).

Esta afirmação, que se tornou a tese fundamental do perspectivismo, obriga Eduardo Viveiros de Castro a insistir que os animais dissociam as formas objetivas ou aparentes das identidades e perspectivas subjetivas, como se as formas fossem meros "envelopes" das perspectivas subjetivas e das identificações ou significações internalizadas dos corpos e comportamentos evidentes. Acho isto um erro fundamental, que contradiz o princípio universal (ao que eu saiba) da cultura indígena da Amazônia, que é a crença na correspondência e interdependência pragmática entre forma aparente (e.g., o aspecto da superfície do corpo produzido pelos adornos corporais, como pinturas, capacetes, penteados, pulseiras, botoques do lábio e orelhas etc.) e conteúdo interno (inclusive de poderes sensoriais e capacidades físicas que constituem a fundação de identidades e perspectivas subjetivas). Por isso os povos indígenas da Amazônia gastam tanto tempo pintando e enfeitando seus corpos: para eles, modificar a forma aparente do corpo é uma instrumentalidade eficaz pela modificação concomitante do seu conteúdo interno, tanto objetivo como subjetivo, assim como de suas relações externas como pessoas sociais. No pensamento indígena, eu acho, a forma das coisas não é nem uma sobrecarga sem conexão intrínseca ao seu conteúdo nem uma categoria classificatória sincrônica numa visão estruturalista de cultura, mas sim uma esquema ou forma dinâmica da atividade transformativa de formação da entidade tanto nos seus aspectos sociais como físicos. Este esquema de atividade formativa, com sua meta de produção e manutenção da forma (ou, subjetivamente, da identidade) da entidade, é a manifestação material do espírito da entidade - a fonte da intenção ou propósito da atividade de se formar segundo o padrão devido da sua espécie. Forma ativa e auto-produzidora é espírito, e 
também é "perspectiva" no sentido epistemológico do perspectivismo.

Acho que chegamos aqui a uma formulação de relevância geral ao pensamento e à consciência social dos povos indígenas da Amazônia. Na perspectiva de seus mitos e de suas práticas rituais e corporais, este nexo de relações entre forma, esquema de atividade, conteúdo, espírito e subjetividade é uma propriedade comum de todas as entidades do mundo - seres humanos, animais, plantas e até algumas entidades não-animadas (e.g., sol, lua e outros objetos celestiais). É, pois, uma propriedade pré- ou não cultural, mesmo se os seres humanos conseguem produzir formas culturais neste processo universal de formação. Este processo, pois, em todas as suas formas naturais e culturais, serve como um tipo de denominador comum de todos os seres qua seres, entre os quais seres humanos não têm prioridade nem papel especial de donos de espírito. Está aqui o ponto de convergência destas ideias sobre o caráter esquemático de formas e a relação de forma, neste sentido, com espírito, com animismo, um conceito fundamental que tem sido retomado por antropólogos como Descola, Casevitz e outros. Assim, a afirmação perspectivista de que os animais conseguem ter espíritos somente através da sua identificação com a gente, que se baseia na suposição de que ter espírito é um traço especificamente humano, parece-me ser mais um erro antropocêntrico do perspectivismo. É um erro, aliás, que impede a devida síntese de perspectivismo com animismo.

Em resumo, estou propondo uma interpretação alternativa dos mitos que foram tomados por Eduardo Viveiros de Castro como a fundação da teoria de perspectivismo. Segundo minha análise, o ponto dos mitos é contar como os animais e os seres humanos, começando de um estado de relativa indiferenciação, acabaram se diferenciando. E, além do mais, como a criação de cultura no sentido contemporâneo desempenhou o papel catalítico neste processo transformativo. Mas isto, por sua vez, remete a uma reconceitualizacão da natureza da própria cultura, tal como é vista na perspectiva destes mitos. Como sugeri um pouco antes, é essencial reconhecer que os seres humanos da era mítica ainda não tinham cultura no sentido completamente desenvolvido que têm na nossa época. Eram os animais, e não os antepassados humanos, que em muitos casos possuíam os traços e utensílios (fogo, arco e flecha, corda de algodão) que se tornaram, depois, as bases da cultura humana. As formas destas coisas quando somente os animais as possuíam, porém, não eram formas completamente culturais: eram ainda objetos achados ou únicos, que os animais não sabiam, ou ao menos não costumavam produzir de maneira generalizada. As possessões proto-culturais dos animais ancestrais, em outras palavras, eram possuídas como objetos, ou formas objetivas, mas seus proprietários não possuíam o segredo do processo de objetivação, ou seja, a capacidade de produção dessas coisas. Esta é a natureza da transformação produzida pelos antepassados míticos dos seres humanos quando eles tomaram o fogo proto-cultural das onças e o utilizaram para acender outros fogos, produzindo assim fogo cultural. Faltou aos analistas estruturalistas, inclusive perspectivistas, do mito de origem do fogo de cozinha - que serve como ponto de partida do grande esforço de Lévi-Strauss de averiguar as bases do pensamento indígena sobre o caráter da cultura humana e sua relação com a natureza através de uma análise de mitos -, notar que não é a cozinha com fogo em si mesmo que representa cultura, mas sim o uso do fogo para acender fogo, ou seja, a meta-cozinha do fogo pelo próprio fogo.

A cozinha das onças, utilizando um fogo que elas mesmas não criaram, só chegou ao meio do caminho entre natureza e cultura. A cultura, na perspectiva dos mitos, não aparece assim nem como uma categoria oposta à natureza e engolindo-a, como no perspectivismo, nem reduzida a um efeito passageiro da natureza em diálogo consigo própria, como no estruturalismo ortodoxo, mas sim como uma espécie de meta-natureza, um produto da 
aplicação do processo esquemático de produção de formas e entidades à produção da produção de si mesmo, como na cozinha do fogo da cozinha.

Campos: Essas suas críticas ao perspectivismo foram ou estão em vias de ser publicadas?

TT: Sim, vão aparecer em um artigo intitulado "The Crisis of Late Structuralism: Animism and Perspectivism", na revista Tipiti ${ }^{9}$.

Campos: Em 2000, após a publicação do livro de Patrick Tierney, Darkness in El Dorado, a American Anthropological Association criou uma comissão para investigar as denúncias, veiculadas nessa obra, contra o antropólogo Napoleon Chagnon. Por muitos anos, antropólogos brasileiros e estrangeiros que trabalham com os Yanomami alertavam a AAA das graves conseqüências éticas do trabalho de Chagnon para esse grupo, mas esses avisos sempre foram ignorados. Qual a sua participação nesse processo? O senhor considera que esse debate mudou a postura dos antropólogos e a antropologia que se faz nos Estados Unidos hoje? O que o episódio nos diz sobre as relações entre a antropologia norte-americana e a antropologia brasileira de um modo geral?

TT: Quero lembrar que muito antes do livro de Patrick Tierney ser publicado eu denunciei publicamente certos aspectos do trabalho de Chagnon e as posições que ele tinha tomado, como acusar os missionários salesianos de genocídio contra os yanomami. E também as mentiras de Chagnon a respeito da investigação entre aspas que ele tinha feito com um companheiro dele, Charles Brewer-Carías - um político direitista venezuelano que também é um empresário da área de mineração -, que ele leva a cabo em territórios indígenas violando as leis venezuelanas. Em 1980, os salesianos circularam críticas aos esforços de Chagnon e Brewer-Carías de cortar a reserva Yanomami para abrir um trecho do território que era protegido para a exploração mineral por Charles Brewer Carías, o que daria a Chagnon o controle absoluto da entrada de outros no restante da reserva e outras coisas. Então Chagnon mobilizou alguns sociobiólogos admiradores do trabalho dele, como Robin Fox e o professor dele, muito prestigiado, Eric Wolf.

O propósito destas cartas dos amigos de Chagnon era que as denúncias que os salesianos tinham circulado sem assinar - e que chegaram a várias pessoas, inclusive a mim, sem identificação da autoria - deveriam ser descartadas como completamente falsas. Eu concordo que quem denuncia uma pessoa publicamente dessa maneira deve se identificar e eles, os salesianos, erraram neste sentido. Mas Chagnon e seus apoiadores se serviram desse erro dos salesianos para tentar descartar completamente toda crítica e todo o conjunto de documentos. Foi então que eu me manifestei em sentido contrário. Num artigo publicado no boletim da American Anthropological Association eu disse que, apesar de não considerar ética a forma de circulação desses documentos, as acusações contra Chagnon e Brewer Carías eram verdadeiras. Embora não estivesse de acordo com o anonimato, eu disse que Chagnon tinha que responder às críticas. Isso foi, eu considero, o salto inicial. Aconteceu mais ou menos cinco anos antes do livro de Tierney.

Campos: Na década de 1980, quando Manuela Carneiro da Cunha foi presidente da ABA, houve uma denúncia que foi ignorada. 
TT: Não foi completamente ignorada. O que aconteceu foi o seguinte: na época eu fazia parte da Comissão de Direitos Humanos da AAA. O presidente da Associação era [Roy] Rappaport, que chegou a nós, membros da comissão, com a denúncia e nos perguntou o que poderíamos fazer. Eu e outros membros da comissão de direitos humanos falamos: "isso não diz respeito tanto a violação de direitos humanos, trata-se de ética profissional, você deve levar o documento para a comissão de ética para que ela faça a investigação dessas acusações". Rappaport foi até a comissão de ética. Acho que em parte para evitar a responsabilidade de responder a estas acusações, a comissão de ética da AAA anunciou que estava se retirando da investigação de casos específicos e que se dedicaria dali para frente somente à articulação de princípios gerais de ética profissional. Dessa maneira as acusações caíram entre duas cadeiras, foram muito mal gerenciadas. Não foi a primeira vez que chegaram acusações contra Chagnon, mas a American Anthropological Association era e continua sempre como uma associação muito tímida, muito politicamente neutra.

Então foi lançado o livro de Tierney. Sabendo que a AAA provavelmente tentaria ignorar as acusações, eu e Leslie Sponsel, que tinha sido o chefe da comissão de direitos humanos, escrevemos uma carta bem inflamada sobre o conteúdo desse livro. Afirmamos na carta que a Associação não poderia evitar tomar uma posição. As acusações que Tierney tinha feito eram graves, gravíssimas, e sugeriam inclusive que Chagnon, na expedição de 1968, tinha sido responsável pela morte de muitas pessoas naquela epidemia e que talvez tivesse sido mesmo responsável por aquela epidemia. Havia muito mais acusações contra Chagnon: a distorção, as mentiras sobre fatos etnográficos, tudo no sentido de representar os Yanomami não somente como os mais violentos, mas como uma sociedade horrorosa. Sugerimos na tal carta que as lideranças deveriam preparar uma investigação e ser capazes de enfrentar o furacão de críticas e a publicidade que seguramente iria se seguir à publicação do livro. Alguém que não sei quem foi, que continua formalmente desconhecido, pegou nossa comunicação, que foi especificamente endereçada a certas pessoas (lideranças da Associação) para levar a cabo uma investigação. Essa pessoa mandou a carta por e-mail a centenas de pessoas e logo começou um escândalo de proporções globais.

Esta carta é o texto de minha autoria (juntamente com o meu parceiro, Leslie) que mais pessoas no mundo todo leram. Nós ficamos no centro desse furacão. Furacão sim, mas furacão de reações contra isso, contra o Chagnon, contra nós por repetirmos as acusações de Tierney sem investigarmos etc. Vocês conhecem essa história. Então a Associação respondeu sugerindo montar uma comissão de investigação, que se chamou informalmente El Dorado Commission, formada por "pessoas brandas". Ou seja, evitou-se incluir alguém que tivesse realmente estudado os Yanomami, porque quase todo mundo que tinha estudado os Yanomami estava contra Chagnon. Nessa comissão se tentou preservar uma aparência de objetividade, mas os esforços da comissão dificilmente poderiam chegar a críticas ao trabalho de Chagnon. A maravilha foi que no final a comissão conseguiu formular umas cinco críticas bem graves contra o trabalho e os pronunciamentos públicos dele. Num esforço transparente de evitar que a comissão pudesse chegar a fazer críticas sérias, sociobiólogos da "coalizão Chagnon" pressionaram a presidente da associação, Louise Lamphere, para indicar um antropólogo próximo de Chagnon, um protegido de Chagnon, que se chama Ray Hames.

Campos: Ele foi aluno do Chagnon. 
TT: Aluno, aliado e implicado em algumas das ações que fizeram parte da lista de acusações contra Chagnon. Foi espantosa essa indicação pela presidente, numa tentativa de apaziguar todo esse choro dos partisans de Chagnon. A despeito de tudo isso, a comissão produziu um relatório que, embora muito mal realizado e mal escrito, continha críticas duras ao comportamento ético de Chagnon e à expedição de James Neel - que, falecido alguns meses antes, tinha sido o grande herói dos sociobiólogos. Seguiram-se os esforços dos apoiadores de Chagnon para desacreditar o relatório. Inicialmente eles introduziram uma moção de censura contra mim e Leslie Sponsel, recomendavam à Associação nos censurar por termos escrito a carta de que acabo de falar. A carga específica contra nós era que nós tínhamos apresentado "testemunhos falsos" das maldades de Chagnon (coisa que não tínhamos feito, uma vez que testemunhamos, em nossa carta, somente o que Tierney tinha dito no livro). Organizaram toda a sociedade de antropologia evolucionista, que chegou, ficou sentada em um ponto, e votou em bloco para censurar a mim e a Leslie. Mas muitos amigos chegaram e a moção de censura foi derrotada. Eles (os amigos de Chagnon e Neel) introduziram então outra moção, agora uma denúncia contra a comissão investigativa por falhas acerca de procedimentos legais. A comissão não era uma entidade jurídica, essas acusações não eram adequadas aos trabalhos da comissão. Eles fizeram um esforço, mas pouca gente da Associação respondeu durante o prazo entre a introdução dessa moção e a votação final, que ocorreu depois de vários meses. A chefe da comissão e a presidente da Associação, que tinha aceitado o relatório, ficaram caladas, não defenderam o relatório da sua própria comissão. Eu, Leslie Sponsel e alguns outros nos colocamos em oposição a essa moção, mas realmente houve falta de liderança e responsabilidade por parte dos membros e das lideranças da Associação. O resultado foi que só 10 ou $12 \%$ dos membros da Associação votaram sim ou não. Destes, dois terços votaram a favor da moção, que defendia que a aprovação do relatório da liderança da Associação deveria ser retirada por causa destas falhas de procedimentos na investigação, pois a moção não tratou de nenhum ponto das conclusões do relatório. Então o relatório ficou, mas as críticas que fez não foram tidas como necessárias. Só restou a aceitação do relatório. A diretoria da Associação praticamente se retirou. Então se tem uma espécie de limbo, algo confuso: a investigação das acusações foi feita, as conclusões críticas não foram refutadas.

Um elemento decisivo foi a indiferença maciça dos membros, as pessoas simplesmente não queriam saber. A Associação era e continua assim. Que efeito tinha esse debate, esse escândalo, sobre a Associação, a ética, a consciência social, a consciência ética? A resposta é zero. Acho que fica tudo como antes. Mais uma vez a AAA falhou por não levar a sério as conclusões críticas sobre a ética de Chagnon. Faltou coragem de realmente enfrentar, de realmente levar a cabo as próprias conclusões da comissão que ela própria tinha apontado. Como a Associação poderia levar a sério as críticas da carta de Manuela Carneiro da Cunha quando não levou a sério as acusações idênticas no relatório de sua própria comissão? Então, isso é hipocrisia em primeiro plano. Eu sempre balanço com esses caras. Vem-me um impulso de simplesmente sair da Associação, depois penso em tentar ficar e criar desconfortos. Mas não tenho saída. Eu realmente tenho desprezo pela conduta das lideranças da Associação e acho a indiferença da grande maioria dos membros decepcionante.

Esta indiferença ou, pior, falta de coragem e vontade política parece ser uma condição bastante generalizada na comunidade antropológica nos Estados Unidos. Para outro exemplo, considerem as ações da associação que se chama SALSA (Society for the Anthropology of Lowland South America). É uma associação de antropólogos que trabalham na Amazônia, que comporta umas setenta pessoas. Eu sugeri que a SALSA deveria tomar uma posição no debate sobre a moção introduzida na AAA contra o relatório da comissão Eldorado e apoiar a proposição 
de que os "procedimentos legais" da comissão não estavam errados, que a moção de reprovação do relatório é que fora errada. Metade dos membros da SALSA presentes se posicionaram contra, argumentando que já falamos o bastante sobre isso, não deveríamos falar mais, que essas discussões políticas só iriam perturbar e até poderiam provocar a dissolução da nossa associação. Finalmente foi votada uma moção adiando definitivamente qualquer discussão sobre o assunto. Essa foi a resposta corajosa desta Associação. Dessa experiência tiro duas conclusões: primeiro, que a luta por padrões éticos eficazes em associações profissionais de antropólogos vai custar um bom tempinho para ser ganha; e, segundo, que as violações dos códigos de ética profissional vão continuar, e provavelmente se propagar com mais freqüência, daqui para frente. 


\section{NOTAS}

1 N.E.: A referência é ao general José Costa Cavalcanti (1918-1991), ministro do Interior de 1969 a 1974.

2 N.E.: Turner, Terence. 1993. "De Cosmologia a História: resistência, adaptação e consciência social entre os Kayapó". In E. Viveiros de Castro e M. Carneiro da Cunha (orgs.). Amazônia: Etnologia e História Indígena. São Paulo: NHII/USP/ FAPESP. pp. 43-66.

3 N.E.: Lave, Jean. 1976. "Eastern Timbira Moiety Systems in Time and Space: a complex structure". In. B. Albert, A. Castel \& M. Guyot (eds.) Actes du Congrès Internationale des Américanistes 42. Paris: Société des Américanistes.

4 N.E.: Turner, Terence. 2006. "Structure, Process, Form". In. Kreinath, Jens; Jan Snoek; Michael Stausberg (eds.). Theorizing Ritual. Brill: NUMEN-Bookseries, pp. 207-246.

5 N.E.: Ver Turner, Terence. 1979. "The Ge and Bororo Societies as Dialectical Systems: a general model". In D. MayburyLewis (ed.) Dialectical Societies. Harvard. 147-178 e "Kinship, household and community structure among the Northern Kayapo". In. D. Maybury-Lewis (ed). Dialectical Societies. Harvard. 179-217. Sobre "hierarquia rotativa", ver também "Lo bello y lo común: desigualdades de valor y jerarquia rotativa entre los kayapo". Revista de Antropologia Social, 11(1): 201-18. Madrid. (2002). Deste artigo há uma versão inglesa: "The beautiful and the common: gender and social hierarchy among the Kayapo". Tipiti: The Journal of the Society for the Anthropology of Lowland South America 1(1): 11-26. (September 2003).

6 N.E.: Turner, Terence. 2008. "Marxian Value Theory: an anthropological perspective". In. David Pedersen (ed.). Values of Value - special issue. Anthropological Theory 8(1): 43-56.

7 Aqui Terence Turner faz referência ao início das publicações de Michel Foucault sobre os mecanismos de poder. Considere-se, por exemplo, que Vigiar e Punir é de 1975.

8 N.E.: Ver nota 2 acima.

9 N.E.: Turner, Terence. 2009. "The Crisis of Late Structuralism: Animism and Perspectivism". Tipiti 7:1. 